\title{
Binary nucleation in acid-water systems. II. Sulfuric acid-water and a comparison with methanesulfonic acid-water
}

\author{
B. E. Wyslouzil, J. H. Seinfeld, and R. C. Flagan \\ Department of Chemical Engineering, California Institute of Technology, Pasadena, California 91125 \\ K. Okuyama \\ Department of Chemical Engineering, Hiroshima University, Saijo-cho, Higashi-Hiroshima, Japan
}

(Received 22 October 1990; accepted 29 January 1991)

\begin{abstract}
This work presents a systematic investigation of binary nucleation rates for sulfuric acid and water and the effect of temperature on these rates at isothermal, subsaturated conditions. The results from nucleation rate measurements for the sulfuric acid $\left(\mathrm{H}_{2} \mathrm{SO}_{4}\right)$-water system are discussed and compared to those previously presented for methanesulfonic acid (MSA)-water [B. E. Wyslouzil, J. H. Seinfeld, R. C. Flagan, and K. Okuyama, J. Chem. Phys. (submitted) ]. Experiments were conducted at relative humidities ( $\mathrm{hh}$ ) ranging from $0.006<\mathrm{Rh}<0.65$, relative acidities $(\mathrm{Ra})$ in the range of $0.04<\mathrm{Ra}<0.46$, and at three temperatures, $T=20,25$, and $30^{\circ} \mathrm{C}$, in the continuous flow mixing-type apparatus described in Paper I. Particles were formed by binary nucleation and grew by condensation as the mixed stream flowed through an isothermal glass tube. Number concentrations observed at the exit of the nucleation and growth tube as a function of $\mathrm{Rh}$ and $\mathrm{Ra}$ are extremely sensitive to the binary nucleation rate, and from these data the nucleation rate was estimated as a function of saturation level and temperature. Particle size distributions were also measured using a specially constructed differential mobility analyzer. As anticipated, the $\mathrm{H}_{2} \mathrm{SO}_{4}$ particles formed by nucleation and growth are much smaller than those formed in the MSA-water experiments, but particle size distribution measurements confirm that most of the particles formed are being observed. The ratio of experimental to theoretical nucleation rates, $J_{\text {expt }} / J_{\text {theor }}$, was found to be a strong function of the predicted number of acid molecules in the critical nucleus for both the $\mathrm{H}_{2} \mathrm{SO}_{4}$-water and MSA-water systems.
\end{abstract}

\section{INTRODUCTION}

The sulfuric acid-water binary has been the traditional model for theoretical studies of the binary nucleation rate expression. ${ }^{1-4}$ It is an important system in the atmosphere, because $\mathrm{H}_{2} \mathrm{SO}_{4}$ is the product of the oxidation of $\mathrm{SO}_{2}$ as well as other naturally occurring sulfur species. The system does present intrinsic experimental difficulties, related to its corrosive properties and its extremely low vapor pressure. Property values are however reasonably well known over essentially the entire range of composition at temperatures near $25^{\circ} \mathrm{C}$. Even the vapor pressure of sulfuric acid has been determined recently to within a factor of about four by Ayers ${ }^{5}$ and Roedel. ${ }^{6}$

The first measurements of nucleation rates in the $\mathrm{H}_{2} \mathrm{SO}_{4}-\mathrm{H}_{2} \mathrm{O}$ system were the expansion chamber results of Reiss et al. ${ }^{7}$ Later however, Schelling and Reiss ${ }^{8}$ concluded that expansion chambers were not appropriate for working with the acid water system in part because of the long times scales required to set up the steady-state cluster distributions relative to the sensitive time of the chamber. Boulaud et al. ${ }^{9}$ observed particle formation between $\mathrm{SO}_{3}$ and water vapor as a function of time, but on the time scale of their experiments nucleation, condensation, and coagulation are all important. Finally, Mirabel and Clavelin ${ }^{10}$ measured the onset of nucleation at $25^{\circ} \mathrm{C}$ using a thermal upward diffusion chamber, but only measurements at $\mathrm{Rh}>1$ were possible because of the low vapor pressure of $\mathrm{H}_{2} \mathrm{SO}_{4}$. In single component ho- mogeneous nucleation, rate data are a considerably more stringent test of theory than simply determining the critical supersaturation. This is certainly the case in binary nucleation as well, and provides the motivation for the current work.

The continuous flow mixing device used to measure nucleation rates in the MSA-water system, ${ }^{11}$ is used here to investigate nucleation in the $\mathrm{H}_{2} \mathrm{SO}_{4}$-water system. The effect of temperature on the nucleation process is investigated for $\mathrm{Ra}$ and $\mathrm{Rh}<1$ in the range from 20 to $30^{\circ} \mathrm{C}$. At very low values of $\mathrm{Ra}$, conditions should approach those that can exist in the atmosphere. Particle size distributions are measured to better understand the competing processes of nucleation and condensation, and to ensure that the majority of the particles produced are large enough to be observed. The nucleation rate data are then compared to the predictions of classical binary nucleation theory and the deviation of the ratio $J_{\text {expt }} / J_{\text {theor }}$ from 1 is investigated.

\section{CHANGES TO THE CONTINUOUS FLOW MIXING DEVICE}

Since detailed descriptions of the experimental procedures and apparatus appear in Paper I, only the basic concept and the changes made in order to work with the $\mathrm{H}_{2} \mathrm{SO}_{4}-$ water system will be discussed here.

In the continuous flow mixing device particle-free gas streams saturated with the desired acid and water vapor are 
rapidly mixed at known temperatures and pressures to create well characterized initial conditions. The mixed stream flows through an isothermal tube in which particles nucleate and grow. The number concentration of particles produced is measured at the outlet of the reactor using a high resolution condensation nucleus counter (CNC) and provides a sensitive measure of the binary nucleation rate. When the number of particles produced is low, condensation rates will not deplete the acid vapor significantly, and nucleation rates may be derived by dividing the total number concentration by the length of time over which nucleation occurs.

The principal difference in the experimental setup from that previously described is in the method used to measure the particle size distributions. A short column $(10 \mathrm{~cm})$ differential mobility analyzer (DMA) ${ }^{12}$ was used in conjunction with the TSI $3020 \mathrm{CNC}$ to improve the lower cutoff for the $<50 \mathrm{~nm}$ particles produced in the experiment. The shorter column length allows the high mobility fine particles to be classified at reasonable voltages and sheath air flow rates, the use of a brass rather than Teflon outlet port reduces the loss of particles due to electrostatic charging, and the $3020 \mathrm{CNC}$ has a lower detection limit than the 3076 CNC used previously. The DMA was run in stepping mode, with voltages changed manually. At least six number concentrations were recorded at each voltage, once steady state was achieved, which were then averaged as part of the inversion process. At particle diameters $\left(D_{p}\right)$ less than $20 \mathrm{~nm}$, the data were corrected for the decreased counting efficiency of the CNC using the data of Ahn and Liu, ${ }^{13}$ Keady et al. ${ }^{14}$ and Bartz et al., ${ }^{15}$ and for diffusional losses in the DMA using the data of Adachi $e t$ al. ${ }^{16}$ Before starting the experiments, it was also necessary to let the equipment run for several days in order to achieve steady and reproducible data. After this initial conditioning period, experimental results were extremely reproducible.

The sulfuric acid acid used in all of the experiments was "Ultrex" high purity $\mathrm{H}_{2} \mathrm{SO}_{4}$ (Aldrich Chemicals) assayed at $97.5 \mathrm{wt} \%$. Because the source of $\mathrm{H}_{2} \mathrm{SO}_{4}$ vapor is a mixture containing $2.5 \mathrm{wt} \%$ water, the expression for Ra must be corrected for acid composition. Equation (3) of Paper I therefore becomes

$$
\mathrm{Ra}=\frac{a_{a} p_{l} p_{a}\left(T_{a b}\right) F_{a}}{p_{a b} p_{a}\left(T_{m}\right)\left[\left(1+Y_{w}\right) F_{h}+F_{d}+F_{a}\right]} .
$$

Here $a_{a}$ is the acid activity over a $97.5 \mathrm{wt} \%$ solution of $\mathrm{H}_{2} \mathrm{SO}_{4}$. As in Paper I, $p_{l}, p_{a b}, p_{a}\left(T_{a b}\right)$, and $p_{a}\left(T_{m}\right)$ are the absolute pressure in the laboratory, the measured acid bubbler pressure, the saturation vapor pressure of the acid at the temperature in the acid bubbler and the saturation vapor pressure of acid at the temperature of the mixer. $F_{h}, F_{d}$, and $F_{a}$ are the flow rates of the humid, dry, and acidic streams respectively, and $Y_{w}$ is the ratio of moles of water vapor per mole of dry air flowing through the water bubbler. The assumption has been made that the ratio of moles of acid to moles of air $Y_{a}$, is approximately equal to zero because the vapor pressure of the acid at $25^{\circ} \mathrm{C}$ is on the order of $1.4 \times 10^{-4}$ Torr. The values for $a_{a}$ are based on the data of Giauque et al. ${ }^{17}$

Although some water vapor will be present at equilibri- um with the $\mathrm{H}_{2} \mathrm{SO}_{4}$ solution, at 97.5 wt $\% \mathrm{H}_{2} \mathrm{SO}_{4}$ the activity of water, $a_{w} \approx 10^{-4}$, is negligible compared to the amount of water vapor entering with the humid stream. Therefore the value of $R h$ is still calculated using Eq. (1) from Paper I.

\section{NUCLEATION RATES AND PARTICLE SIZE BEHAVIOR}

Experiments with the $\mathrm{H}_{2} \mathrm{SO}_{4}$-water binary were performed at relative acidities of $0.45,0.25,0.15$, and 0.10 , relative humidities of 0.28 and 0.14 , and temperatures of 20,25 , and $30^{\circ} \mathrm{C}$. All of the experimental conditions investigated are summarized in Table I.

Figure 1 shows typical data collected on the variation of number concentration as a function of the saturation level and temperature for $T=25^{\circ} \mathrm{C}$. The symbols represent the average of all the values observed at the given conditions, with the extremes indicated by the vertical error bars. Horizontal error bars represent the calculated uncertainty in the saturation levels, $( \pm 5 \%)$, which is the result of the uncertainties in the flow and temperature controls. The uncertainties in the flows dominate the total uncertainty, since each flow is accurate to $\pm 3 \%$. Data represented by *'s show the internal consistency of the data and demonstrate that the number concentration observed at a given set of conditions is independent of the direction of approach to that condition. The repeatability of the experiments, once steady operating conditions have been achieved, is illustrated in Fig. 1 where experiments at $\mathrm{Ra}=0.45$ and 0.25 were repeated one and three days apart, respectively. At the same conditions of saturation and temperature, measured number concentrations agree to within a factor of 3 or 4 .

TABLE I. Experimental conditions investigated in the total number experiments.

\begin{tabular}{cccc}
\hline \hline $\begin{array}{c}\text { Experiment } \\
\text { number }\end{array}$ & $\begin{array}{c}\text { Temperature } \\
\left({ }^{\circ} \mathrm{C}\right)\end{array}$ & $\begin{array}{c}\text { Relative } \\
\text { acidity }\end{array}$ & $\begin{array}{c}\text { Relative } \\
\text { humidity }\end{array}$ \\
\hline 20.09 & 25.1 & $0.454-0.455$ & $0.012-0.286$ \\
20.10 & 24.7 & $0.453-0.454$ & $0.012-0.291$ \\
20.11 & 25.0 & $0.246-0.249$ & $0.028-0.434$ \\
20.12 & 25.0 & $0.150-0.156$ & $0.094-0.601$ \\
20.13 & 24.9 & $0.113-0.116$ & $0.156-0.644$ \\
20.14 & 24.9 & $0.114-0.456$ & $0.140-0.144$ \\
20.15 & 25.1 & $0.087-0.456$ & $0.281-0.284$ \\
20.28 & 25.4 & $0.245-0.248$ & $0.046-0.444$ \\
20.16 & 20.2 & $0.455-0.456$ & $0.044-0.333$ \\
20.17 & 19.8 & $0.247-0.250$ & $0.045-0.432$ \\
20.18 & 19.7 & $0.147-0.154$ & $0.109-0.560$ \\
20.19 & 19.7 & $0.113-0.115$ & $0.397-0.647$ \\
20.20 & 19.7 & $0.153-0.455$ & $0.141-0.143$ \\
20.21 & 19.7 & $0.116-0.456$ & $0.280-0.283$ \\
20.22 & 29.5 & $0.448-0.450$ & $0.006-0.274$ \\
20.23 & 29.8 & $0.245-0.248$ & $0.006-0.419$ \\
20.24 & 30.0 & $0.150-0.156$ & $0.011-0.479$ \\
20.25 & 30.1 & $0.112-0.116$ & $0.027-0.417$ \\
20.26 & 30.0 & $0.046-0.453$ & $0.136-0.139$ \\
20.27 & 30.2 & $0.039-0.454$ & $0.268-0.272$ \\
\hline \hline
\end{tabular}




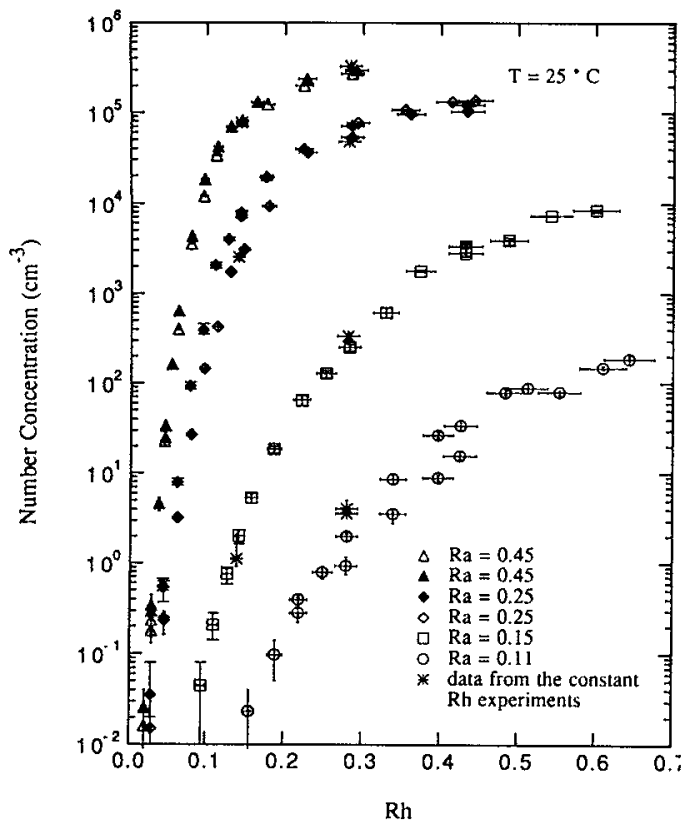

FIG. 1. The observed number concentrations as a function of relative humidity at $T=25^{\circ} \mathrm{C}$.

It is clear from the data presented here that the number of particles produced is extremely sensitive to both the saturation levels and temperature. Because the vapor pressure of water is so much higher than that of the acid, even high nucleation rates will not perturb the relative humidity of the mixed stream. Furthermore, if the production of particles is low, nucleation and condensation will not deplete the acid vapor significantly on the time scale of the experiment. In this case, the nucleation rate can be estimated by dividing the number concentration of particles produced by the length of time over which nucleation occurs. With the low final number concentration and a residence time of only $18 \mathrm{~s}$, coagulation will not occur to any significant extent, and as discussed previously, ${ }^{11}$ losses of particles or vapor to the walls can also be neglected.

The initial steep increase in the number concentration curves (Fig. 1), from $N<0.1 \mathrm{~cm}^{-3}$ up to about $N=1000$ $\mathrm{cm}^{-3}$, corresponds to the region of constant nucleation rate along the nucleation and growth tube. At higher levels of saturation, the curves flatten out, as the available acid vapor is depleted and nucleation is quenched well within the flow tube. These data cannot be used to derive nucleation rates because the time over which significant nucleation is occurring is unknown.

Figures 2 through 7 illustrate the variation of the nucleation rates with saturation level derived from the experimental number concentrations. The data for a given constant saturation level all fall on straight lines, except for a few points at $T=30^{\circ} \mathrm{C}$. These points, corresponding to $\mathrm{Rh}<0.02$, actually fall below the lower limit of the flowmeter calibrations and uncertainty in the actual value of $R h$ requires that these points be discarded from further analysis.

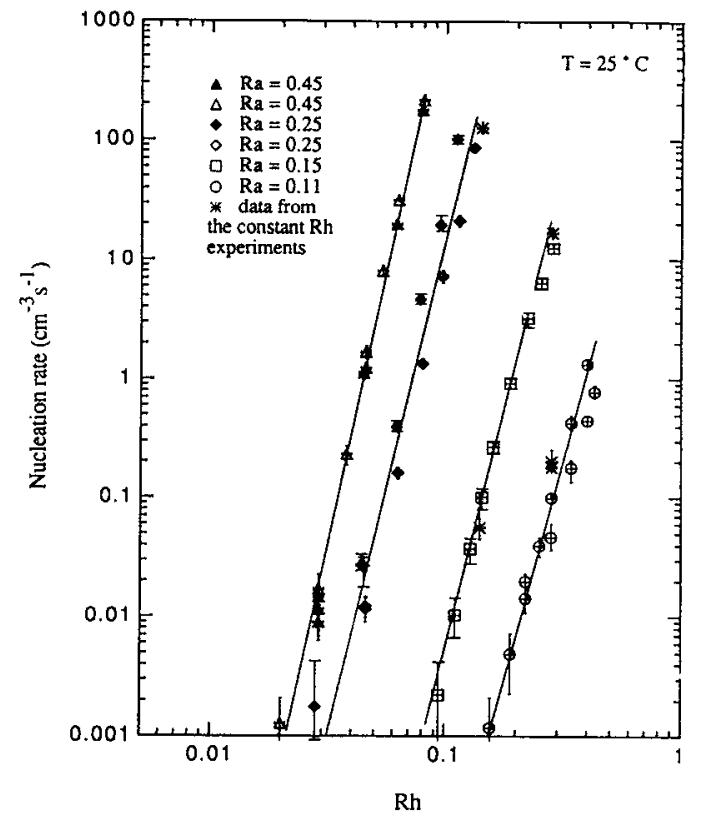

FIG. 2. Nucleation rates of $\mathrm{H}_{2} \mathrm{SO}_{4}-\mathrm{H}_{2} \mathrm{O}$ as a function of relative humidity at four different relative acidities and $T=25^{\circ} \mathrm{C}$. The repeatability of the experiements is illustrated by the two experiments at $\mathrm{Ra}=0.45$, where data were taken one day apart, and the two experiments at $\mathrm{Ra}=0.25$ where data were taken three days apart. The lines connect the data points only.

Figures 8 through 10 illustrate the saturation levels that correspond to $J=0.01,1$, and $100 \mathrm{~cm}^{-3} \mathrm{~s}^{-1}$ that have been derived from the experimental nucleation rate data. Figure 10 clearly shows the rapid increase in the level of Ra required

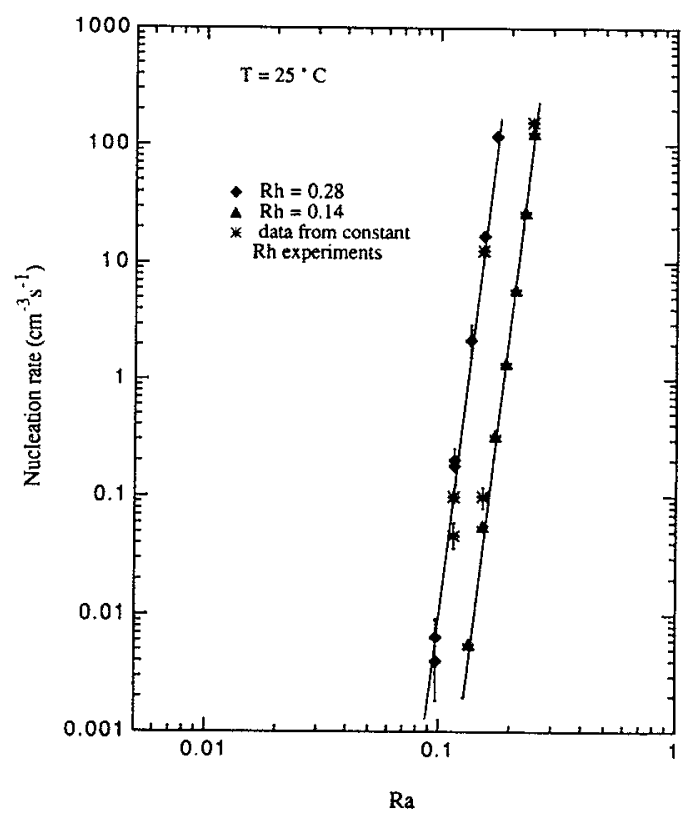

FIG. 3. Nucleation rates of $\mathrm{H}_{2} \mathrm{SO}_{4}-\mathrm{H}_{2} \mathrm{O}$ as a function of relative acidity at two different relative humidities and $T=25^{\circ} \mathrm{C}$. The lines connect the data points only. 


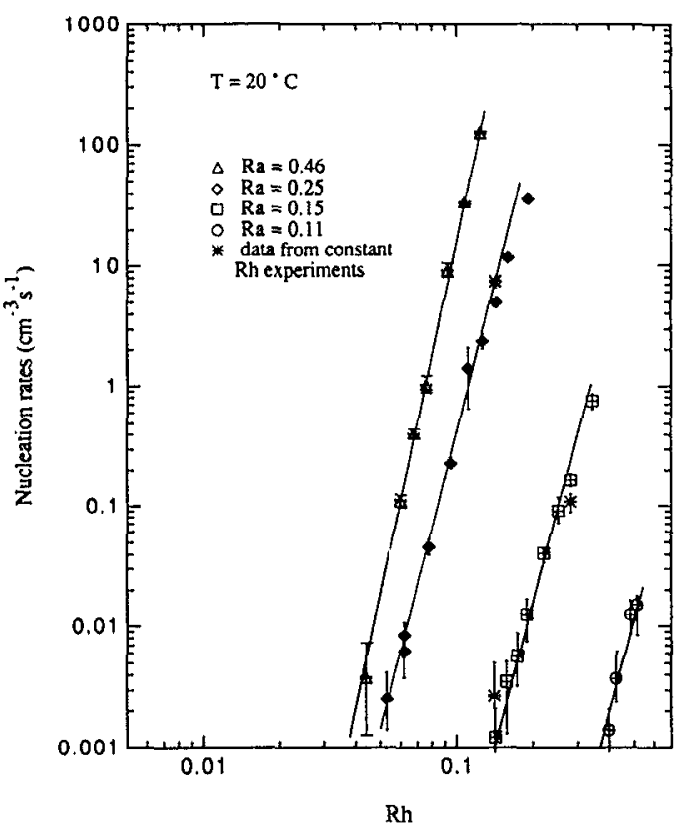

FIG. 4. Nucleation rates of $\mathrm{H}_{2} \mathrm{SO}_{4}-\mathrm{H}_{2} \mathrm{O}$ as a function of relative humidity at four different relative acidities and $T=20^{\circ} \mathrm{C}$. The lines connect the data points only.

to maintain a given nucleation rate as $\mathrm{Rh}$ decreases, indicative of the approach to single component nucleation.

The effect of temperature on the nucleation rate is clearly demonstrated in Fig. 11, where experimental and theoretical rates corresponding to $\mathrm{Rh}=0.28$ at $T=20,25$, and $30^{\circ} \mathrm{C}$ are plotted. A temperature increase of $5{ }^{\circ} \mathrm{C}$ corresponds to an increase in the observed nucleation rate of two

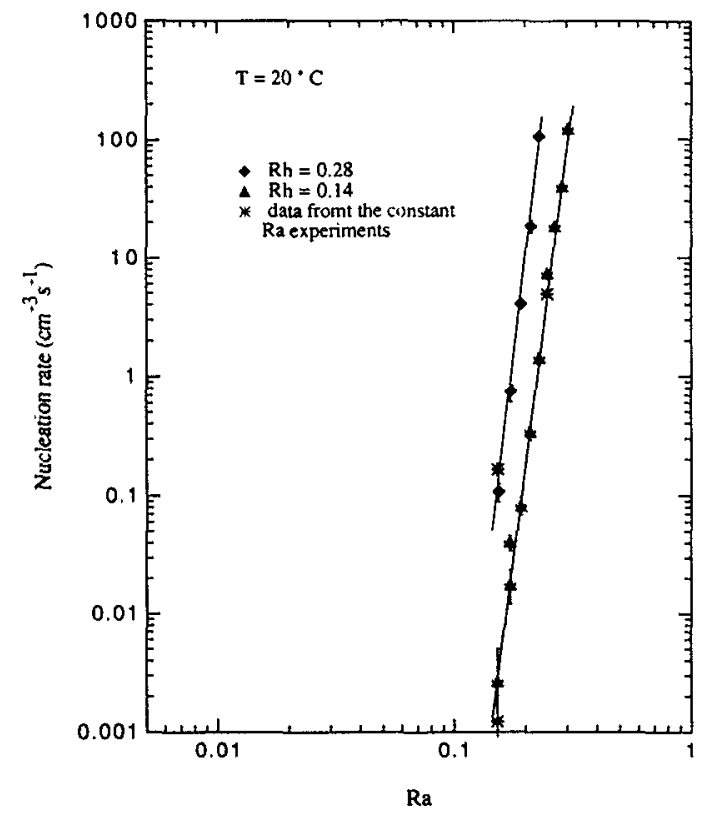

FIG. 5. Nucleation rates of $\mathrm{H}_{2} \mathrm{SO}_{4}-\mathrm{H}_{2} \mathrm{O}$ as a function of relative acidity at two different relative humidities and $T=20^{\circ} \mathrm{C}$. The lines connect the data points only.

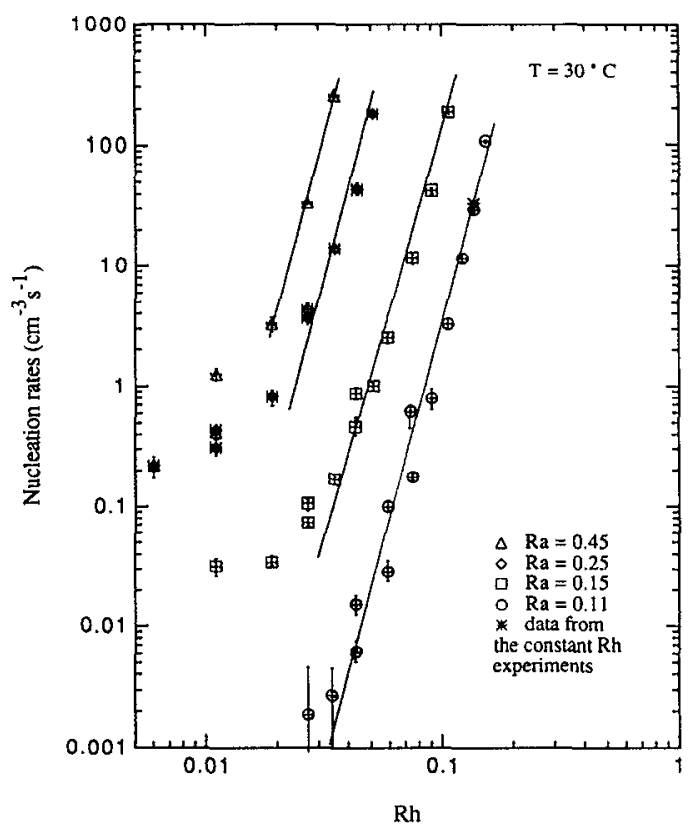

FIG. 6. Nucleation rates of $\mathrm{H}_{2} \mathrm{SO}_{4}-\mathrm{H}_{2} \mathrm{O}$ as a function of relative humidity at four different relative acidities and $T=30^{\circ} \mathrm{C}$. The lines connect the data points only. Deviation from the straight line behavior at low $\mathrm{Rh}$ is due to flowmeter calibration inaccuracies.

to four orders of magnitude. This observation differs significantly from the behavior predicted by classical binary nucleation theory, where the only discernable change is a slight increase in the steepness of the rate curves as temperature increases, however it does agree with the observations in single component nucleation.

The binary nucleation rate expression used to calculated

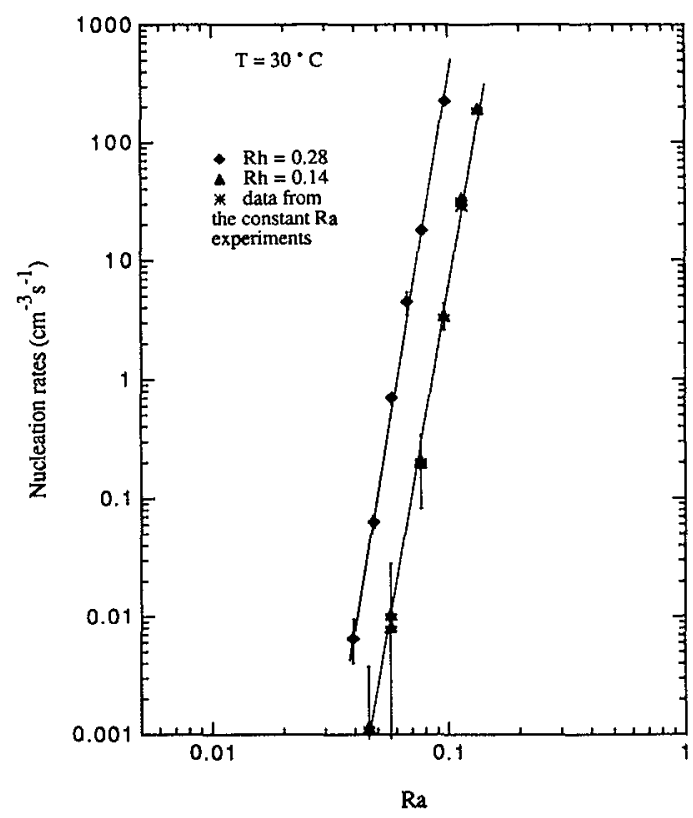

FIG. 7. Nucleation rates of $\mathrm{H}_{2} \mathrm{SO}_{4}-\mathrm{H}_{2} \mathrm{O}$ as a function of relative acidity at two different relative humidities and $T=30^{\circ} \mathrm{C}$. The lines connect the data points only. 


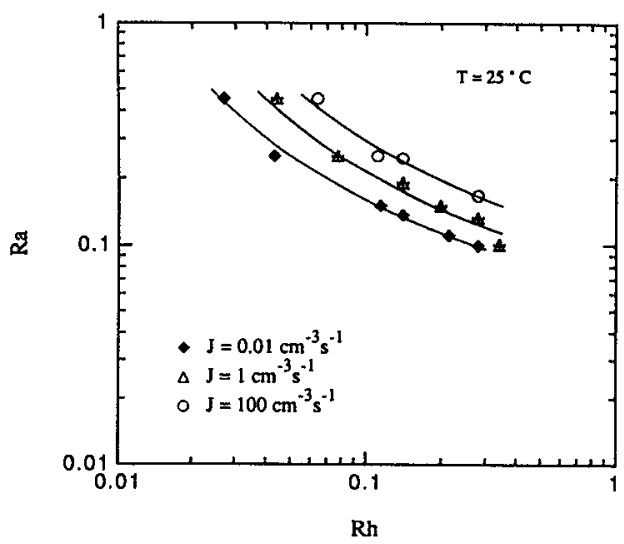

FIG. 8. The variation of nucleation rates with saturation levels for the $\mathrm{H}_{2} \mathrm{SO}_{4}-\mathrm{H}_{2} \mathrm{O}$ binary at $J=0.01,1$, and $100 \mathrm{~cm}^{-3} \mathrm{~s}^{-1}$ and $T=25^{\circ} \mathrm{C}$.

the nucleation rate at the initial mixed stream conditions was that developed by Jaecker-Voirol and Mirabel ${ }^{17}$ and described in detail in Paper $I$. The saddle point of the free energy surface was found by a discrete search that allowed only integral numbers of acid and water molecules in the critical cluster, and which included the effect of hydrate formation in the gas phase. The data correlation programs developed by Kreidenweis and Seinfeld ${ }^{18}$ and the vapor pressure of pure sulfuric acid measured by Ayers ${ }^{5}$ were used in all of the calculations.

Particle size distributions were measured for only a limited number of cases. Volume distributions $d V / d \ln D_{p}$, were calculated from the measured number distributions, $d N / d \ln D_{p}$. Figure 12 illustrates a typical particle size distribution. As in almost all of the cases observed, the peak in the number distribution appears to be within the measuring range of the instrumentation even with the corrections due to diffusion losses and counting efficiency of the CNC for particles $<20 \mathrm{~nm}$. Although there is not enough data to perform a thorough analysis of the behavior of the peak diameter with respect to changes in $\mathrm{Ra}$ and $\mathrm{Rh}$, the distribu-

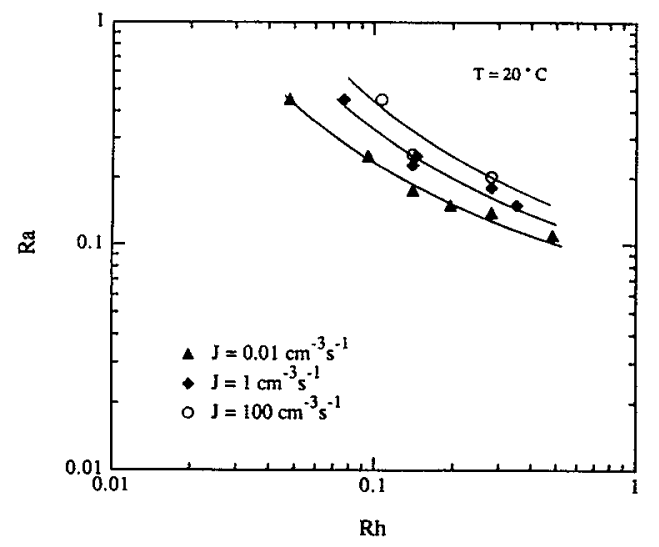

FIG. 9. The variation of nucleation rates with saturation levels for the $\mathrm{H}_{2} \mathrm{SO}_{4}-\mathrm{H}_{2} \mathrm{O}$ binary at $J=0.01,1$, and $100 \mathrm{~cm}^{-3} \mathrm{~s}^{-1}$ and $T=20^{\circ} \mathrm{C}$.

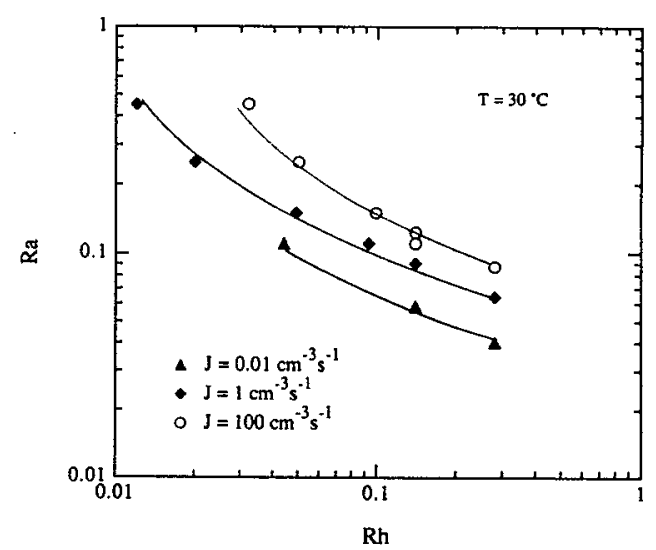

FIG. 10. The variation of nucleation rates with saturation levels for the $\mathrm{H}_{2} \mathrm{SO}_{4}-\mathrm{H}_{2} \mathrm{O}$ binary at $J=0.01,1$, and $100 \mathrm{~cm}^{-3} \mathrm{~s}^{-1}$ and $T=30^{\circ} \mathrm{C}$.

tions do imply that most of the particles produced are being counted and that the nucleation rate measurements are not significantly affected by particles not visible to the TSI 3020 CNC.

The particle size distributions are well described by lognormal distributions and from the value of $\sigma_{g}$, the standard deviation obtained from the fit of the volume distribution curves, a value of the polydispersity factor, $\alpha_{p}=\exp \left(-\ln ^{2}\left(\sigma_{g}\right)\right)$, was estimated as $\alpha_{p}=0.7$. The polydispersity factor is used in the integral model for nucleation and growth, described in Paper I, to correct for the overestimation of the condensation rate that occurs because the aerosol is assumed to be monodisperse. The value of $\alpha_{p}$ for the $\mathrm{H}_{2} \mathrm{SO}_{4}-\mathrm{H}_{2} \mathrm{O}$ is higher than that found for the

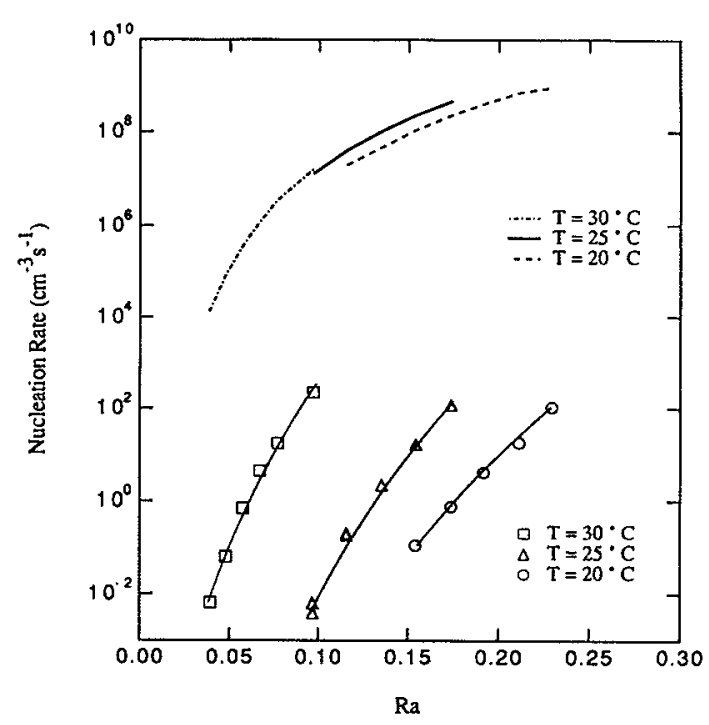

FIG. 11. The observed changes in nucleation rate with temperature are compared to those predicted by classical binary nucleation theory for $\mathrm{Rh}=0.28$ and $T=20,25$, and $30^{\circ} \mathrm{C}$. The observed rates are far more sensitive to temperature than the calculated rates. 


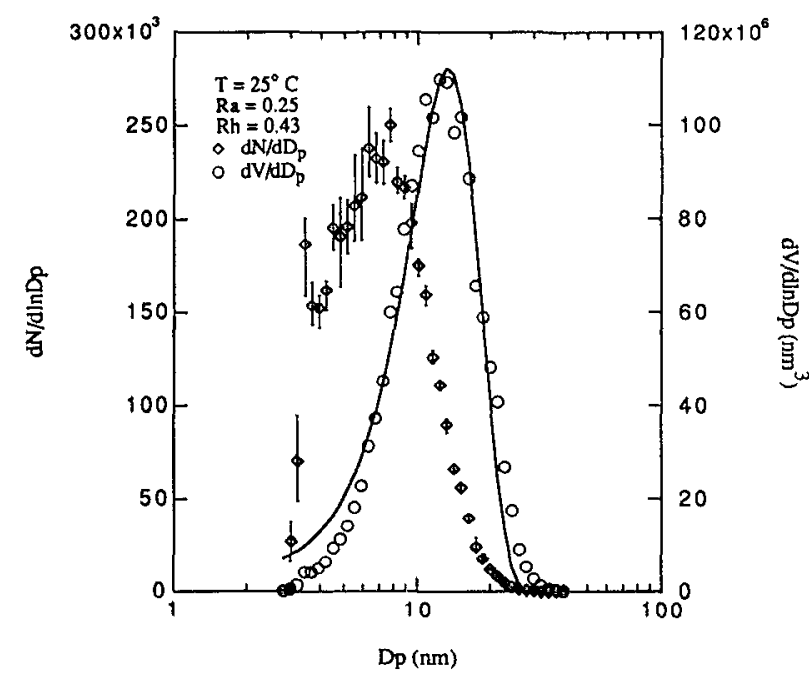

FIG. 12. A typical number and volume distribution for the $\mathrm{H}_{2} \mathrm{SO}_{4}-\mathrm{H}_{2} \mathrm{O}$ system. The solid line is a log normal fit to the volume data and illustrates that the produced aerosol is reasonably described in this manner.

MSA $-\mathrm{H}_{2} \mathrm{O}$ aerosols, where $\alpha_{p}=0.6$, reflecting the more monodisperse size distributions observed.

A major objective of the present work is to compare measured nucleation rates with the predictions of classical binary nucleation theory. The plots of the experimental nucleation rates against the theoretical nucleation rates on loglog coordinates, Figs. 13-15, show that a straight line relationship exists between the two rates for each constant saturation level experiment conducted. However at a given temperature, the data from the different experiments do not all fall on a single straight line, and experiments at constant $\mathrm{Ra}$ have distinctly different slopes from those at constant $\mathrm{Rh}$. Thus the application of a single correction factor to the binary nucleation rate expression at a given temperature, which

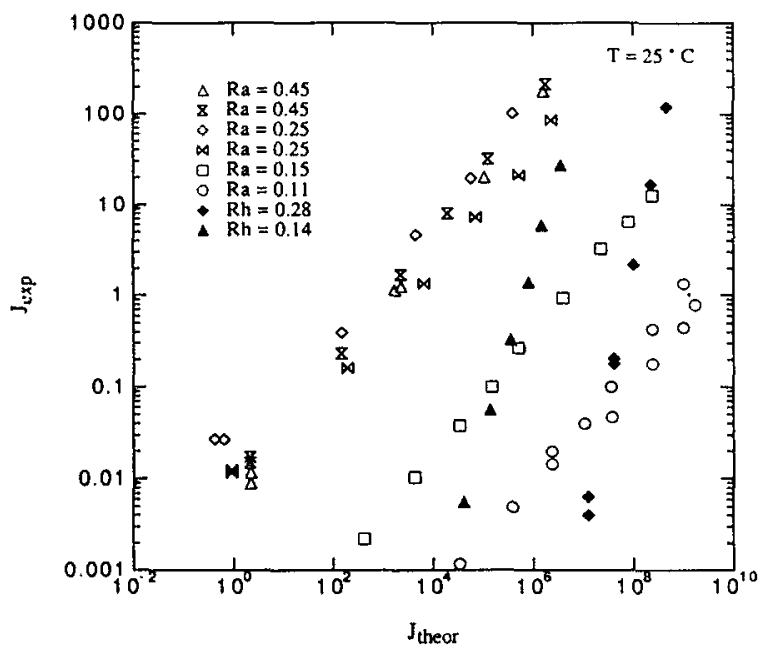

FIG. 13. A straight line correspondence between the experimental nucleation rates and the rates calculated by classical binary nucleation theory exists for each $\mathrm{H}_{2} \mathrm{SO}_{4}-\mathrm{H}_{2} \mathrm{O}$ data set at $T=25^{\circ} \mathrm{C}$.

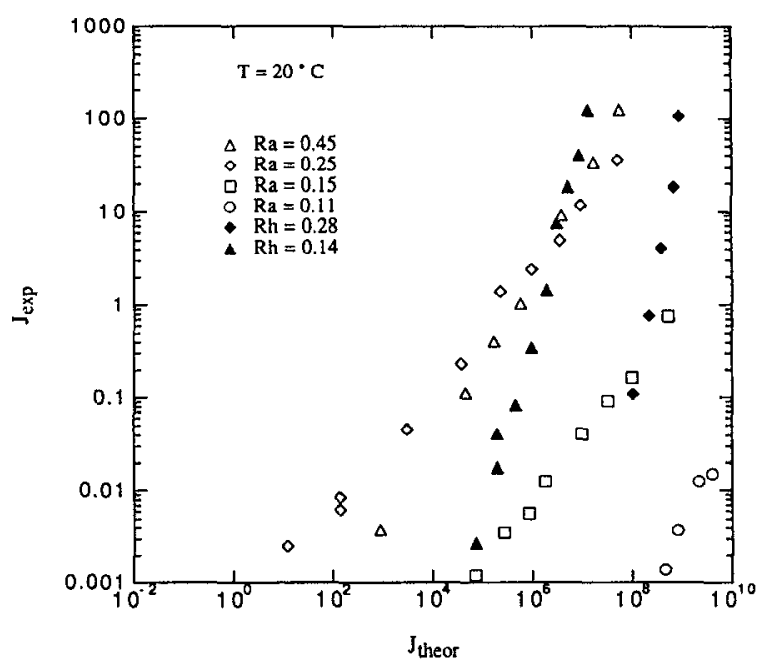

FIG. 14. A straight line correspondence between the experimental nucleation rates and the rates calculated by classical binary nucleation theory exists for each $\mathrm{H}_{2} \mathrm{SO}_{4}-\mathrm{H}_{2} \mathrm{O}$ data set at $T=20^{\circ} \mathrm{C}$.

was found to give a reasonable description of the experimental results in the case of MSA-water, cannot describe the $\mathrm{H}_{2} \mathrm{SO}_{4}-\mathrm{H}_{2} \mathrm{O}$ data.

In each of the figures, however, a clear trend emerges. As the initial level of acidity increases, the value of the ratio $J_{\text {expt }} / J_{\text {theor }}$ increases. This suggests that $J_{\text {expt }} / J_{\text {theor }}$ should be a function of a characteristic concentration. One concentration available is that of the critical nucleus as predicted by classical binary nucleation theory. Although $J_{\text {expt }} / J_{\text {theor }}$ was found to vary with the mole fraction of acid in the critical nucleus, a strong correlation was found by plotting $J_{\text {expt }} / J_{\text {theor }}$ against the number of acid molecules in the critical nucleus. As illustrated in Fig. 16, there is a strong relationship between the two variables of interest, and the data

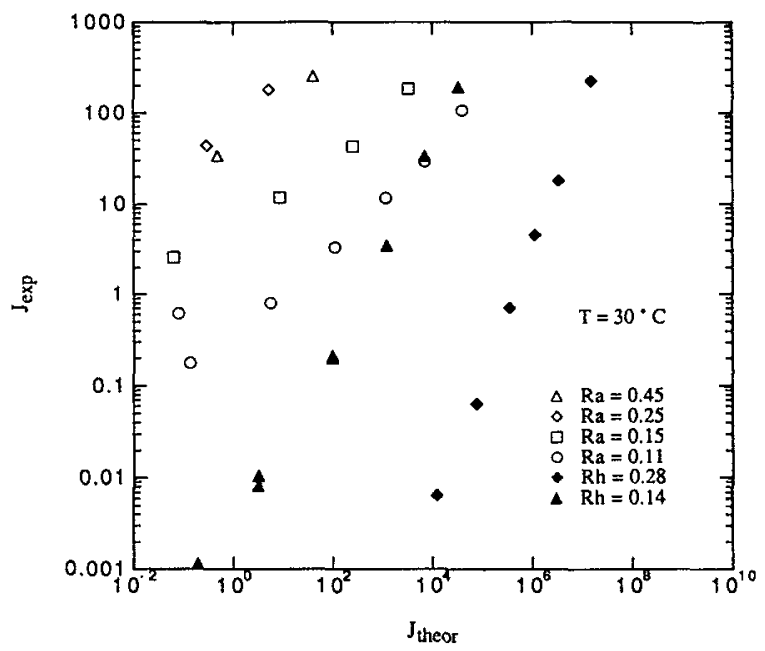

FIG. 15. A straight line correspondence between the experimental nucleation rates and the rates calculated by classical binary nucleation theory exists for each $\mathrm{H}_{2} \mathrm{SO}_{4}-\mathrm{H}_{2} \mathrm{O}$ data set at $T=30^{\circ} \mathrm{C}$. 


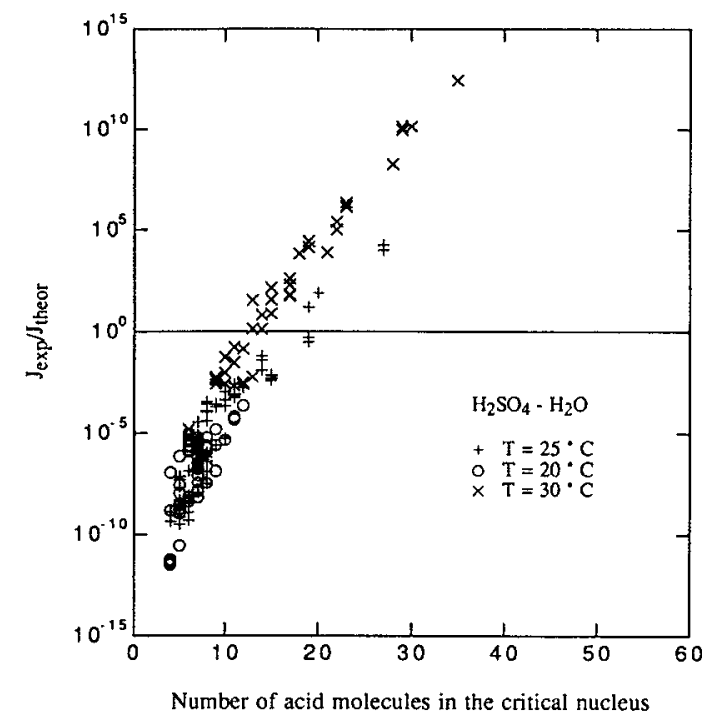

FIG. 16. Variation of the correction factor to classical binary nucleation theory with the number of acid molecules in the critical nucleus for the $\mathrm{H}_{2} \mathrm{SO}_{4}-\mathrm{H}_{2} \mathrm{O}$ system.

from all three temperatures fall on a single band with good agreement in the regions of overlap.

The line for perfect agreement between theory and experiment, $J_{\text {expt }} / J_{\text {theor }}=1$, has been included in Fig. 16 for reference. The discrepancy between experiment and theory ranges over more than 20 orders of magnitude as the predicted number of acid molecules in the critical nucleus varies from about 4 to 30 . A decrease in the number of acid molecules in the critical nucleus corresponds to increasing nucleation rates, thus this graph confirms that overall in the $\mathrm{H}_{2} \mathrm{SO}_{4}-\mathrm{H}_{2} \mathrm{O}$ system the predicted rates increase far more rapidly than the observed rates. Figure 16 represents a useful way to present the discrepancy between the experimental and theoretical nucleation rates when the true critical nucleus composition is unknown.

In retrospect it should not be surprising to find a compositional dependence of $J_{\text {expt }} / J_{\text {theor }}$. In single component nucleation the critical nucleus composition is well defined, while in binary nucleation this composition corresponds to that at the saddle point of the free energy surface, a function that depends strongly on the number of acid molecules present. Work with the dioctylphthalate (DOP)-dibutylphthalate (DBP) system by Okuyama et al. ${ }^{19}$ showed that the best overall correction factor for the binary nucleation measurements could also be quite different from that of either of the individual components, with no smooth transition between the two. This in some senses also implies a dependence of $J_{\text {expt }} / J_{\text {theor }}$ on the critical nucleus composition.

Although Fig. 11 shows that the experimental nucleation rates depend strongly on the temperature, the compositional dependence of $J_{\text {expt }} / J_{\text {theor }}$ clearly dominates any temperature dependence of this function over the range of temperatures investigated in this study. A wider range of temperatures would be required to try and separate the two effects.

\section{A. Comparison with previous data on the nucleation of $\mathrm{H}_{2} \mathrm{SO}_{4}-\mathrm{H}_{2} \mathrm{O}$}

The only available data with which to compare the present results are the $25^{\circ} \mathrm{C} \mathrm{H}_{2} \mathrm{SO}_{4}-\mathrm{H}_{2} \mathrm{O}$ experiments of Mirabel and Clavelin. ${ }^{10}$ The strong dependence of nucleation rate on temperature precludes a comparison with the results of Reiss et al., ${ }^{6}$ where experimental conditions were far below room temperature. Figure 17 presents the current data for $J=1 \mathrm{~cm}^{-3} \mathrm{~s}^{-1}$ as a function of acid and water saturation levels, along with the first few points taken from Fig. 3 of Mirabel and Clavelin. ${ }^{10}$ The curve $^{10}$ suggested for extrapolating these data to lower $\mathrm{Rh}$ has also been included to facilitate comparison with the present data set.

As Rh approaches zero, the present data show the expected sharp increase in the $\mathrm{Ra}$ which corresponds to the approach to single component nucleation. If the present data set is extrapolated in a simple manner to higher values of $R h$, they lie about 1 order of magnitude above the data of Mirabel and Clavelin. ${ }^{10}$ This agreement is not unreasonable, considering the difficulty involved in working with the $\mathrm{H}_{2} \mathrm{SO}_{4}-\mathrm{H}_{2} \mathrm{O}$ system.

\section{B. Comparison between $\mathrm{H}_{2} \mathrm{SO}_{4}$ and MSA}

To ascertain whether MSA behaves in a manner analogous to that of $\mathrm{H}_{2} \mathrm{SO}_{4}$, a chemically similar compound, the measured nucleation rates for MSA-water from Paper I were compared to the corresponding theoretical rates. As illustrated in Fig. 18, there are good straight line relationships between the two rates on log-log coordinates. As anticipated, at $T=19^{\circ} \mathrm{C}$ all of the data lie close to a single straight line corresponding to $J_{\text {expt }} / J_{\text {theor }}=10^{-8}$. The close correspondence of all the data to the single line $J_{\text {expt }} / J_{\text {theor }}=10^{-8}$, is consistent with the good modeling fit possible with a single correction factor found for this temperature in Paper I. In similar plots at $T=25$ and $30^{\circ} \mathrm{C}$ [available as supplementary material from PAPS (Ref. 20) ], the data were spread out, as was the case for $\mathrm{H}_{2} \mathrm{SO}_{4}$, but the trend was different. However, if all of the data are

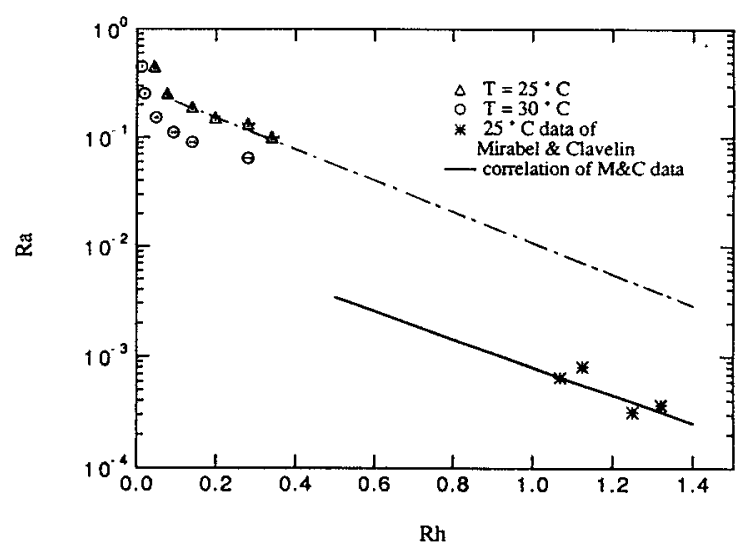

FIG. 17. Comparison of the results from the present work for $J=1$ $\mathrm{cm}^{-3} \mathrm{~s}^{-1}$ to those of Mirabel and Clavelin (Ref. 10). 


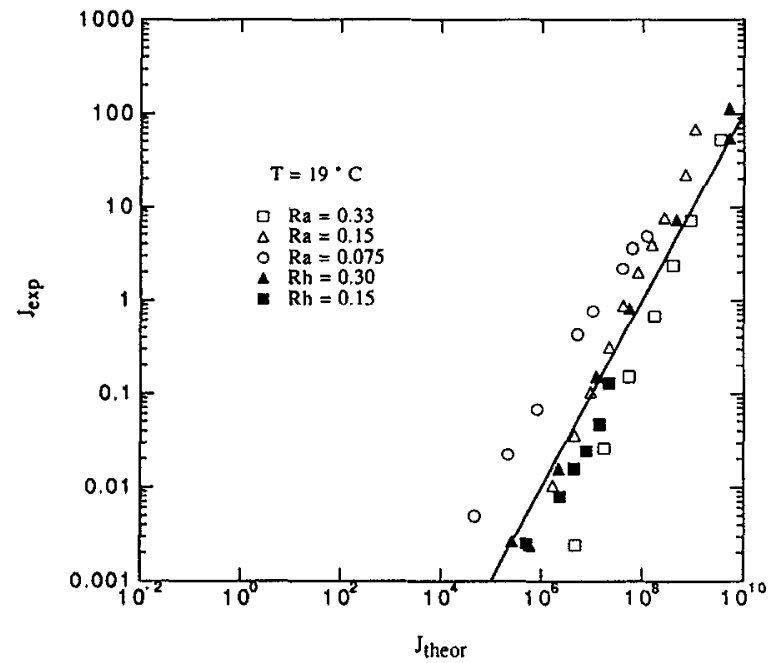

FIG. 18. The correspondence between the experimental nucleation rate and the theoretical rate for $\mathrm{MSA}-\mathrm{H}_{2} \mathrm{O}$ at $19^{\circ} \mathrm{C}$. The data all lie close to the line $J_{\text {expt }} / J_{\text {them }}=10 \%$.

plotted, in Fig. 19, as $J_{\text {expt }} / J_{\text {theor }}$ vs the number of acid molecules in the critical nucleus, the same behavior is found as in the case of $\mathrm{H}_{2} \mathrm{SO}_{4}$. Once again compositional effects dominate the changes in $J_{\text {expt }} / J_{\text {theor }}$ over the temperature range investigated in these experiments.

From classical nucleation theory, we expect nucleation rates for the $\mathrm{H}_{2} \mathrm{SO}_{4}-\mathrm{H}_{2} \mathrm{O}$ binary to be substantially higher than for the MSA $-\mathrm{H}_{2} \mathrm{O}$ binary. In general this was found to be true and Fig. 20 compares the experimental and predicted results for $\mathrm{Rh}=0.15$ and $T=25^{\circ} \mathrm{C}$. Once again the experiments and theory show the same trends, albeit severely offset in terms of the actual values.

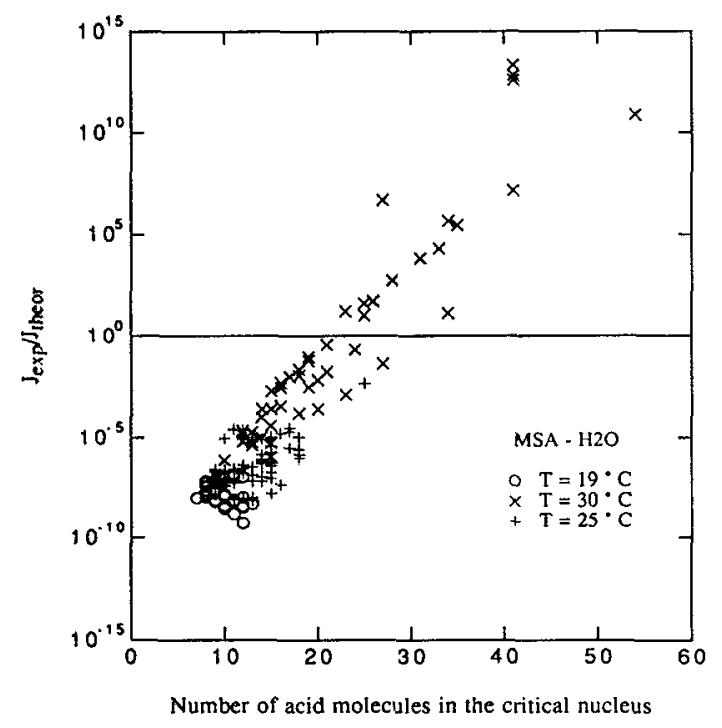

FIG. 19. Variation of the correction factor to classical binary nucleation theory with the number of acid molecules in the critical nucleus for the $\mathrm{MSA}-\mathrm{H}_{2} \mathrm{O}$ system.

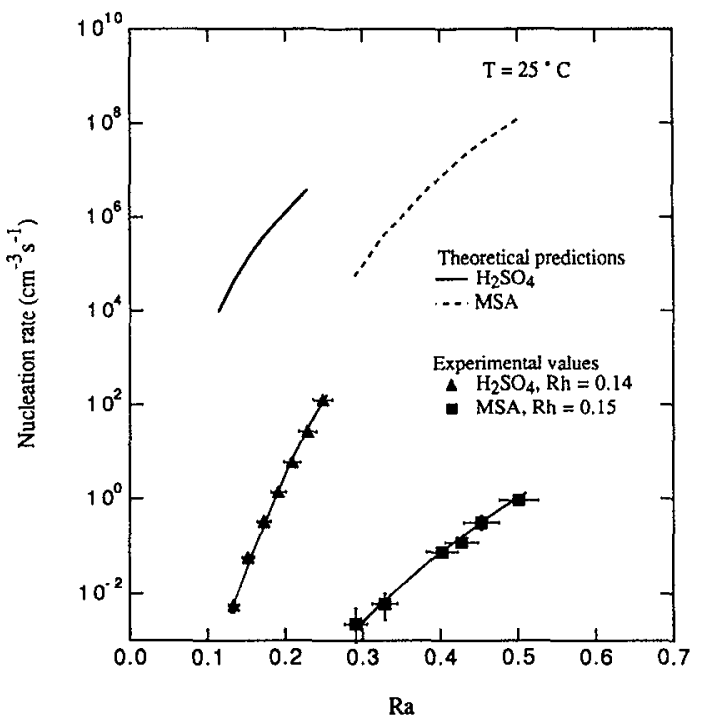

FIG. 20. Comparison of the observed and theoretical nucleation rates for the $\mathrm{H}_{2} \mathrm{SO}_{4}-\mathrm{H}_{2} \mathrm{O}$ system with those of the MSA- $\mathrm{H}_{2} \mathrm{O}$ system at $\mathrm{Rh}=0.15$ and $T=25^{\circ} \mathrm{C}$.

\section{Simulation of the continuous flow apparatus}

The integral model described in Paper I was used here to ascertain that the assumptions regarding constant nucleation rates along the length of the reactor were valid. With the strong dependence of the correction factor on composition it is not possible to model the system in the same way as for MSA. Several test cases were run for $J^{0}=100$ and 10 $\mathrm{cm}^{-3} \mathrm{~s}^{-1}$ using the correction factors found for the given initial conditions. In all cases the nucleation rates and acid saturations remained essentially constant along the length of the nucleation and growth tube, thus verifying the assumption that in these situations condensation onto the nucleating particles is not dominating the gas to particle conversion process.

\section{SUMMARY AND CONCLUSIONS}

The nucleation rates measured using a continuous flow mixing type device were presented for the $\mathrm{H}_{2} \mathrm{SO}_{4}$-water binary for $\mathrm{Ra}$ and $\mathrm{Rh}<1$ and as a function of temperature for $T=20,25$, and $30^{\circ} \mathrm{C}$. The nucleation rates varied from $J=0.01$ to $100 \mathrm{~cm}^{-3} \mathrm{~s}^{-1}$ and were strong functions of both saturation level and temperature, increasing with temperature by two to four orders of magnitude for a temperature increase of $5{ }^{\circ} \mathrm{C}$. In contrast to single component nucleation, the temperature dependent behavior was much stronger than that predicted by classical nucleation theory.

For the $\mathrm{H}_{2} \mathrm{SO}_{4}$-water binary plots of $\log \left(J_{\text {expt }}\right)$ vs $\log \left(J_{\text {theor }}\right)$ were linear for a given saturation level, however at a single temperature the ratio of $J_{\text {expt }} / J_{\text {theor }}$ was clearly not constant. Rather, the ratio $J_{\text {expt }} / J_{\text {theor }}$ was a stronger function of the predicted number of acid molecules in the critical nucleus. Overall, the ratio $J_{\text {expt }} / J_{\text {theor }}$ was a stronger function of composition than temperature over the range of temperature investigated. The same results held for the 
MSA-water binary when these data were analyzed in a similar manner.

As anticipated, when comparing the results for the two acid-water systems, the nucleation rates of $\mathrm{H}_{2} \mathrm{SO}_{4}$-water were much higher than those of MSA-water in the range of values investigated. The slopes of the rate curves were also steeper, again in agreement with theory, and the average particle size was much smaller for the $\mathrm{H}_{2} \mathrm{SO}_{4}$-water aerosol than for the MSA-water aerosol.

\section{ACKNOWLEDGEMENTS}

The authors gratefully acknowledge the assistance of Sonia Kreidenweis who provided computer programs used to correlate the physical property data and simulate the experiments. This work was supported by National Science Foundation Grant No. ATM-9003186 and by the Alberta Heritage Scholarship Trust Fund (B.E.W.).

${ }^{1}$ G. J. Doyle, J. Chem. Phys. 35, 795 (196I).

${ }^{2}$ W. J. Shugard, R. H. Heist, and H. Reiss, J. Chem. Phys. 61, 5298 (1974).

${ }^{3}$ A. Jaecker-Voirol, P. Mirabel, and H. Reiss, J. Chem. Phys. 87, 4849 (1987).

${ }^{4}$ A. Jaecker-Voirol, P. Mirabel, and H. Reiss, J. Chem. Phys. 88, 3518 (1987).
${ }^{5}$ G. P. Ayers, R. W. Gillett, and J. L. Gras, Geophys. Res. Lett. 7, 433 (1980).

${ }^{6}$ W. Roedel, J. Aerosol Sci. 10, 375 ( 1979).

${ }^{7}$ H. Reiss, D. I. Margolese, and F. J. Schelling, J. Colloid Interface Sci. 56, $511(1976)$.

${ }^{8}$ F. J. Schelling and H. Reiss, J. Colloid Interface Sci. 83, 246 ( 1981 )

${ }^{9}$ D. Boulaud, G. Madelaine, D. Vilga, and J. Bricard, J. Chem. Phys. 66, 4854 (1977).

${ }^{10}$ P. Mirabel and J. L. Clavelin, J. Chem. Phys. 68, 5020 (1978).

"B. E. Wyslouzil, J. H. Seinfeld, R. C. Flagan, and K. Okuyama, J. Chem. Phys. (submitted)

${ }^{12}$ Y. Kousaka, K. Okuyama, M. Adachi, and T. Mimura, J. Chem. Eng. Japan 19, 401 (1986).

${ }^{\text {t3 }}$ K. H. Ahn and B. Y. H. Liu, J. Aerosol Sci. 21, 263 (1990),

${ }^{14}$ P. B. Keady, V. L. Denler, G. J. Sem, M. R. Stolzenburg, and P. H. McMurray, in Atmospheric Aerosols and Nucleation, edited by P. E. Wagner and G. Vali (Springer-Verlag, 1988), p. 190.

${ }^{15}$ H. Bartz, H. Fissan, C. Helsper, Y. Kousaka, K. Okuyama, N. Fukishima, P. B. Keady, S. Kerrigan, S. A. Fruin, P. H. McMurray, D. Y. Pui, and M. R. Stolzenburg, J. Aerosol Sci. 16, 443 (1985).

${ }^{16}$ M. Adachi, K. Okuyama, Y. Kousaka, S. W. Moon, and J. H. Seinfeld, Aerosol Sci. Techn. 12, 225 (1990).

${ }^{17}$ W. F. Giauque, E. W. Hornung, J. E. Kunzler, and T. R. Rubin, J. Am. Chem. Soc. 82, 62 (1960).

${ }^{14} \mathrm{~S}$. Kreidenweis and J. H. Seinfeld, Atmos. Environ., 22, 283 (1988).

${ }^{19}$ K. Okuyama, Y. Kousaka, S. Kreidenweis, R. C. Flagan, and J. H. Seinfeld, J. Chem. Phys. 89, 6442 (1988).

${ }^{20}$ See AIP document no. PAPS JCPSA-94-6842-9 for 9 pages of supplementary material. Order by PAPS number and journal reference from American Institute of Physics, Physics Auxiliary Publication Service, 335 East 45th Street, New York, NY 10017. The price is $\$ 1.50$ for each microfiche ( 98 pages) or $\$ 5.00$ for photocopies of up to 30 pages, and $\$ 0.15$ for each additional page over 30 pages. Airmail additional. Make checks payable to the American Institute of Physics. 